\title{
Simian T-Lymphotropic Virus Type I
}

National Cancer Institute

\section{Source}

National Cancer Institute. Simian T-Lymphotropic Virus Type I. NCI Thesaurus. Code C14277.

A single-stranded reverse-transcribing RNA retrovirus of the genus deltaretrovirus that infects a wide range of non-human primates. 